Research Paper

\title{
The learning curves of robotic and three-dimensional laparoscopic surgery in cervical cancer
}

\author{
Xue-Lian Li1,2, Dan-Feng Du ${ }^{1,2}$, Hua Jiang $1,2 \bowtie$ \\ 1. Department of Gynecology, Obstetrics \& Gynecology Hospital, Fudan University, Shanghai, China. \\ 2. Shanghai Key Laboratory of Female Reproductive Endocrine-Related Diseases, Shanghai, China. \\ $\triangle$ Corresponding author: Hua Jiang, Obstetrics \& Gynecology Hospital, Fudan University, 419 Fang-Xie Road, Shanghai 200011, China. E-mail: \\ jianghua@fudan.edu.cn. Fax: +86 2163455090. \\ () Ivyspring International Publisher. Reproduction is permitted for personal, noncommercial use, provided that the article is in whole, unmodified, and properly cited. See \\ http://ivyspring.com/terms for terms and conditions.
}

Received: 2016.06.30; Accepted: 2016.09.18; Published: 2016.11.25

\begin{abstract}
BACKGROUND: The 3D laparoscopy systems and robotic systems have been introduced into clinical practice for a few years. But the comparison of robotic and 3D laparoscopic gynecologic surgery is still needed.

OBJECTIVE: To retrospectively compare the learning curves of robotic and 3D laparoscopic hysterectomy and pelvic lymphadenectomy in cervical cancer.

STUDY DESIGN: The operational duration, blood loss, peritoneal drainage of first 24 hours after operation, total hospitalization days, hospitalization days after operation, lymph nodes collected, learning curves and cost of robotic and 3D laparoscopic hysterectomy and pelvic lymphadenectomy in cervical cancer performed by one experienced surgeon were studied.

RESULTS: There was one surgeon who performed 37 cases of robotic and 24 cases of 3D laparoscopic hysterectomy and pelvic lymphadenectomy, and the turning point of learning curves was case $13^{\text {th }}$ and case $10^{\text {th }}$. The differences of duration of operation, blood loss, peritoneal drainage of first 24 hours after operation, total hospitalization days, hospitalization days after operation, lymph nodes collected and perioperative complications were not statistically significant. But the cost of each robotic operation was higher than 3D operation.

CONCLUSIONS: The turning point of the learning curve of 3D laparoscopic hysterectomy and pelvic lymphadenectomy is earlier than that of robotic sugery in patients with cervical cancer, and there is no obvious benefit from robotic surgery than $3 \mathrm{D}$ surgery in the terms of short-term medical index and hospitalization cost.
\end{abstract}

Key words: robotic laparoscopy; 3D laparoscopy; learning curve; hysterectomy and pelvic lymphadenectomy.

\section{Introduction}

The first 3D laparoscopy systems have been introduced into clinical practice for about 30 years, while the Da Vinci ${ }^{\circledR}$ system (Intuitive Surgical Inc, Sunnyvale CA, USA) was authorized for gynecologic surgery in April 2005 and its three-dimensional (3D) vision and a higher degree of forceps freedom had provided advantages of minimally invasive surgery [1-4]. Some previous studies showed that robot-assisted surgery in benign gynecological diseases had no obvious advantage [5-7]. One study showed that well-trained laparoscopic surgeons may not really benefit from 3D robot systems if 3D laparoscopy is available [8]. Another paper even pointed out that it was about time to start a critical discussion as to whether we should drastically limit, or even abandon the use of robot-assisted laparoscopic surgery and focus on more cost-effective strategies of healthcare improvement in an era of worldwide economic crisis [9]. The comparison of robotic and 3D laparoscopic surgery is still needed. How are the 3D laparoscopy systems and the Da Vinci ${ }^{\circledR}$ systems doing in patients with cervical cancer? 
So we performed the present study to retrospectively compare the learning curves of robotic and 3D laparoscopic hysterectomy and pelvic lymphadenectomy in cervical cancer.

\section{Materials and methods}

The Da Vinci ${ }^{\circledR}$ system and 3D laparoscopy system have been introduced to the Obstetrics and Gynecology Hospital of Fudan University, Shanghai, China in recent two years. Most robot-assisted and 3D laparoscopic operations were hysterectomy and pelvic lymphadenectomy. We retrospectively studied robot-assisted and 3D laparoscopic hysterectomy and pelvic lymphadenectomy in cervical cancer

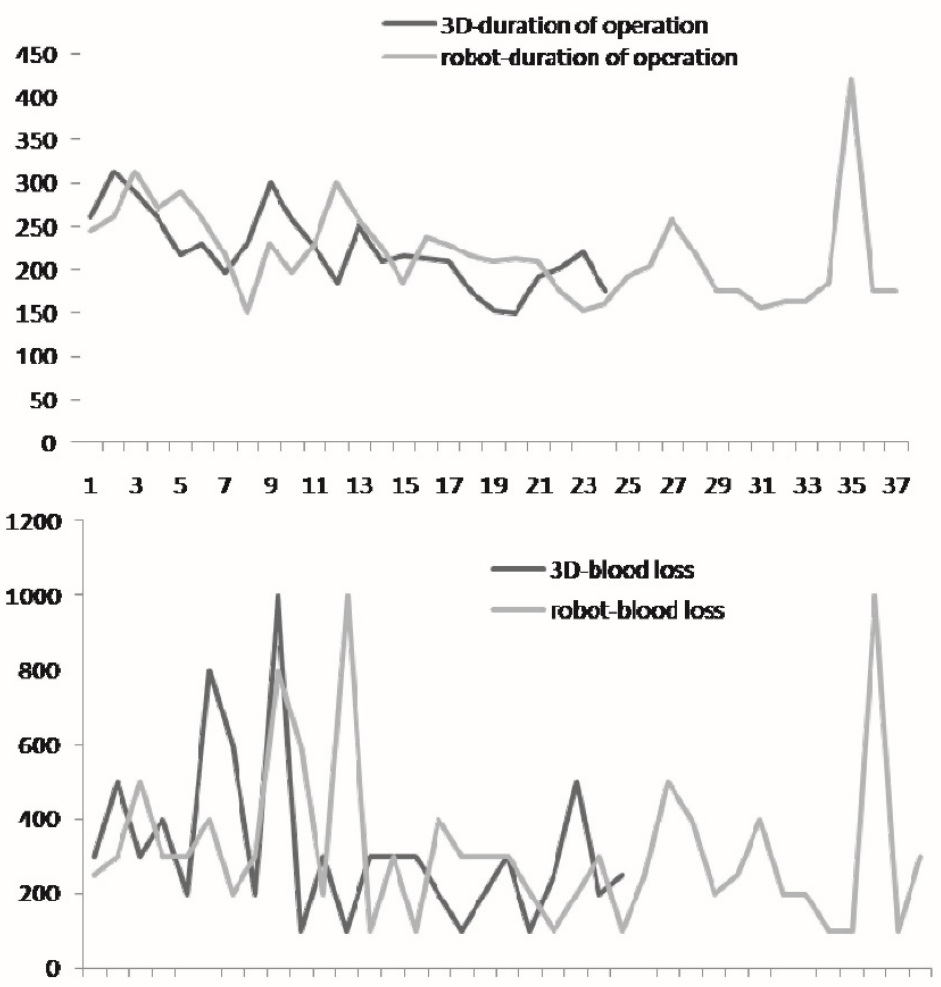

$\begin{array}{lllllllllllllllllll}1 & 3 & 5 & 7 & 9 & 11 & 13 & 15 & 17 & 19 & 21 & 23 & 25 & 27 & 29 & 31 & 33 & 35 & 37\end{array}$

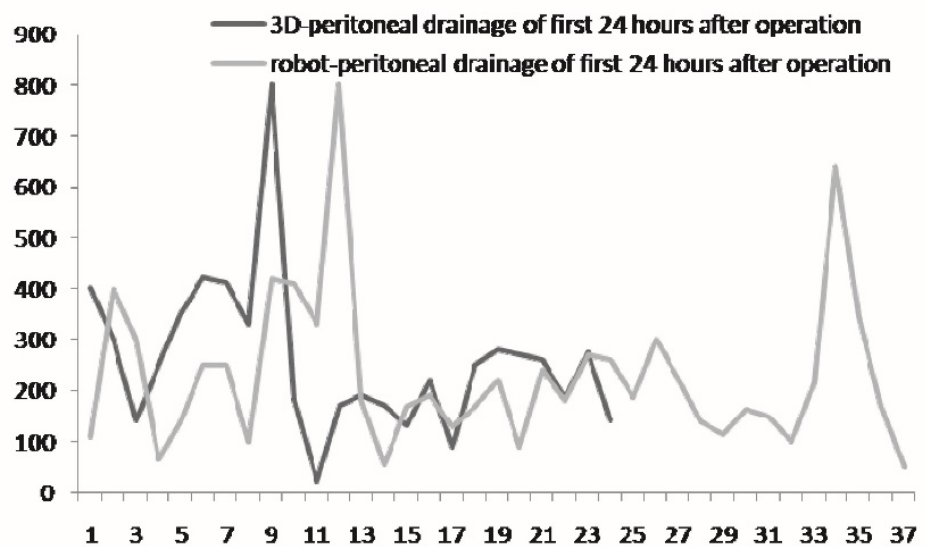

Figure 1. The learning curves of one same surgeon (first 37 cases of robot-assisted surgery vs. first 24 cases of $3 D$ laparoscopic surgery). performed by one experienced surgeon during the same period. This senior surgeon had more than 30 years experiences of abdominal hysterectomy and pelvic lymphadenectomy and also 20 years experiences of conventional laparoscopic surgery. The data of cases included were collected retrospectively. The duration of operation, blood loss, peritoneal drainage of first 24 hours after operation, total hospitalization days, hospitalization days after operation, the lymph nodes collected, the learning curves and the cost of each operation were studied.

\section{Statistical analysis}

All analyses were performed with SPSS statistics 17.0. Independent-samples $T$ test (two-sided) was used to compare means, weighting Chi-square test was used to compare rates, and $\mathrm{P}$ value $<0.05$ was considered statistically significant. $95 \%$ confidence interval of the difference $(95 \% \mathrm{CI})$ was also shown.

\section{Results}

There was one surgeon who performed 37 cases of robot-assisted hysterectomy and pelvic lymphadenectomy and 24 cases of 3D laparoscopic hysterectomy and pelvic lymphadenectomy in cervical cancer during the same period. The stages of all these 61 cases included with cervical cancer were shown as Table 1, and there was no statistically significant difference between two groups.

There were 2 cases of blood loss which need blood transfusion and 1 case of ureteral injury which need indwelling ureteral stent in robot group, and 1 case of blood loss which need blood transfusion in 3D group. No other short-term complication was recorded. The difference of the rate of perioperative complications was not statistically significant $(8.11 \%$ in robot group vs. $4.17 \%$ in $3 \mathrm{D}$ group, $\mathrm{P}=0.94)$.

The learning curves of this same surgeon were shown as Figure 1. The turning point of robot-assisted hysterectomy and pelvic lymphadenectomy was case $13^{\text {th }}$. We compared the first 12 cases and the other 25 cases after the turning point, shown as Table 2. The duration of operation and blood loss both decreased after the turning point, and the differences were statistically significant. The peritoneal drainage of first 24 hours after operation also decreased although it did not reach the statistical significance. The turning point of 3D laparoscopic hysterectomy and pelvic lymphadenectomy was case $10^{\text {th }}$, and 
the comparison of the first 9 cases and the other 15 cases after the turning point was shown as Table 3. The duration of operation, blood loss and the peritoneal drainage of first 24 hours after operation all decreased after the turning point and all of these differences were statistically significant.

Then we compared the robot-assisted versus 3D laparoscopic hysterectomy and pelvic lymphadenectomy performed by this same surgeon, shown as Table 4. The differences of duration of operation, blood loss, peritoneal drainage of first 24 hours after operation, total hospitalization days, hospitalization days after operation, and the lymph nodes collected were not statistically significant. Exclude the basic costs such as the upfront purchase costs and the annual maintenance fees of both groups, the procedure-specific cost of each operation in robot

Table 2. The comparison of the first 12 cases and the 25 cases after the turning point in robot group.

\begin{tabular}{|c|c|c|c|c|c|}
\hline event & group & $\begin{array}{l}\text { cases } \\
\text { (n) }\end{array}$ & Mean $\pm S D$ & $95 \% \mathrm{CI}$ & P value \\
\hline \multirow{2}{*}{$\begin{array}{l}\text { Duration of } \\
\text { operation }\end{array}$} & First 12 cases & 12 & $246.83 \pm 45.93$ & \multirow[t]{2}{*}{$4.99,78.84$} & \multirow[t]{2}{*}{$0.03^{*}$} \\
\hline & Since $13^{\text {th }}$ cases & 25 & $204.92 \pm 54.27$ & & \\
\hline \multirow[t]{2}{*}{ Blood loss } & First 12 cases & 12 & $429.17 \pm 252.68$ & 10.09, & \multirow[t]{2}{*}{$0.04^{*}$} \\
\hline & Since $13^{\text {th }}$ cases & 25 & $268.00 \pm 190.33$ & 312.25 & \\
\hline \multirow{2}{*}{$\begin{array}{l}\text { Peritoneal } \\
\text { drainage after } \\
\text { operation } \\
\text { (24hours) }\end{array}$} & First 12 cases & 12 & $297.92 \pm 202.10$ & -6.31 , & \multirow[t]{2}{*}{0.06} \\
\hline & Since $13^{\text {th }}$ cases & 25 & $198.20 \pm 116.33$ & 205.74 & \\
\hline
\end{tabular}

Table 3. The comparison of the first 9 cases and the 15 cases after the turning point in 3D laparoscopic surgery group.

\begin{tabular}{|c|c|c|c|c|c|}
\hline event & group & $\begin{array}{l}\text { cases } \\
\text { (n) }\end{array}$ & Mean \pm SD & $95 \% \mathrm{CI}$ & $\begin{array}{l}\mathrm{P} \\
\text { value }\end{array}$ \\
\hline \multirow{2}{*}{$\begin{array}{l}\text { Duration of } \\
\text { operation }\end{array}$} & First 9 cases & 9 & $255.00 \pm 40.05$ & \multirow[t]{2}{*}{$22.36,83.24$} & \multirow[t]{2}{*}{$0.00^{*}$} \\
\hline & Since $10^{\text {th }}$ cases & 15 & $202.20 \pm 31.43$ & & \\
\hline \multirow[t]{2}{*}{ Blood loss } & First 9 cases & 9 & $477.78 \pm 277.39$ & \multirow{2}{*}{$\begin{array}{l}27.51 \\
461.38\end{array}$} & \multirow[t]{2}{*}{$0.03^{*}$} \\
\hline & Since $10^{\text {th }}$ cases & 15 & $233.33 \pm 109.65$ & & \\
\hline $\begin{array}{l}\text { Peritoneal } \\
\text { drainage after } \\
\text { operation } \\
\text { (24hours) }\end{array}$ & First 9 cases & 9 & $377.78 \pm 181.51$ & $\begin{array}{l}80.29 \\
297.67\end{array}$ & $0.00^{*}$ \\
\hline
\end{tabular}

group was much higher than that in $3 \mathrm{D}$ group (RMB $30021.00 \pm 3716.15$ vs. RMB $215814.79 \pm 2875.02)$, and the difference was statistically significant $(\mathrm{P}=0.00)$.

We also compared the cases after the turning point both in robotic and 3D laparoscopic surgery group, shown as Table 5. The differences of duration of operation, blood loss, and peritoneal drainage of first 24 hours after operation were not statistically significant.

Table 1. The stages of all cases included with cervical cancer.

\begin{tabular}{llllll}
\hline & IA1 & IB1 & IB2 & IIA1 & Total \\
& $\mathrm{N}(\%)$ & $\mathrm{N}(\%)$ & $\mathrm{N}(\%)$ & $\mathrm{N}(\%)$ & $\mathrm{N}$ \\
\hline Robot group & $4(16.67 \%)$ & $16(66.67 \%)$ & $1(4.17 \%)$ & $3(12.50 \%)$ & 24 \\
3D group & $8(21.62 \%)$ & $24(64.86 \%)$ & $0(0.00 \%)$ & $5(13.51 \%)$ & 37 \\
\hline
\end{tabular}

Table 4. The comparison of robot-assisted versus 3D laparoscopic hysterectomy and pelvic lymphadenectomy.

\begin{tabular}{llllll}
\hline event & group & $\mathrm{N}$ & Mean \pm SD & $95 \% \mathrm{CI}$ & P value \\
\hline Duration of & 3D & 24 & $222.00 \pm 42.90$ & $-20.84,33.16$ & 0.65 \\
operation & robot & 37 & $215.84 \pm 56.28$ & & \\
Blood loss & 3D & 24 & $325.00 \pm 220.67$ & $-102.75,133.30$ & 0.80 \\
& robot & 37 & $309.73 \pm 227.80$ & & \\
Peritoneal & 3D & 24 & $259.67 \pm 153.34$ & $-50.91,111.32$ & 0.46 \\
drainage after & robot & 37 & $229.46 \pm 155.52$ & & \\
operation & & & & & \\
(24hours) & & & & & 0.98 \\
Total & 3D & 24 & $15.54 \pm 4.10$ & $-2.29,2.24$ & \\
hospitalization & robot & 37 & $15.57 \pm 4.46$ & & 0.73 \\
Hospitalization & 3D & 24 & $10.29 \pm 3.30$ & $-1.40,1.99$ & \\
after operation & robot & 37 & $10.00 \pm 3.19$ & & \\
Lymph nodes & 3D & 24 & $18.08 \pm 6.37$ & $-1.50,5.55$ & \\
collected & robot & 37 & $16.05 \pm 6.93$ & & \\
Cost of each & 3D & 24 & $30021.00 \pm 3716.15$ & $-1.87 \mathrm{E} 5,-1.84 \mathrm{E} 5$ & $0.00^{*}$ \\
operation(RMB) & robot & 37 & $215814.79 \pm 2875.02$ & & \\
\hline Note: * means statistically significant. & & &
\end{tabular}

Note: * means statistically significant.

Table 5. The comparison of the cases after the turning point in robotic and 3D laparoscopic surgery group.

\begin{tabular}{|c|c|c|c|c|c|}
\hline event & group & cases $(n)$ & Mean \pm SD & $95 \% \mathrm{CI}$ & $P$ value \\
\hline \multirow[t]{2}{*}{ Duration of operation } & 3D group (after the turning point) & 15 & $202.20 \pm 31.43$ & \multirow{2}{*}{$\begin{array}{l}-33.90 \\
28.46\end{array}$} & \multirow[t]{2}{*}{0.86} \\
\hline & Robotic group (after the turning point) & 25 & $204.92 \pm 54.27$ & & \\
\hline \multirow[t]{2}{*}{ Blood loss } & 3D group (after the turning point) & 15 & $233.33 \pm 109.65$ & \multirow{2}{*}{$\begin{array}{l}-143.93, \\
74.59\end{array}$} & \multirow[t]{2}{*}{0.53} \\
\hline & Robotic group (after the turning point) & 25 & $268.00 \pm 190.33$ & & \\
\hline \multirow{2}{*}{$\begin{array}{l}\text { Peritoneal drainage after } \\
\text { operation ( } 24 \text { hours) }\end{array}$} & $3 \mathrm{D}$ group (after the turning point) & 15 & $188.80 \pm 73.85$ & \multirow{2}{*}{$\begin{array}{l}-77.33 \\
58.53\end{array}$} & \multirow[t]{2}{*}{0.78} \\
\hline & Robotic group (after the turning point) & 25 & $198.20 \pm 116.33$ & & \\
\hline
\end{tabular}

\section{Discussion}

The learning curve stands for the obstacles during learning a new technique in surgery, which is necessary to evaluate the teaching and clinical safety. Current 3D systems provided excellent perception of depth and spatial resolution, and the transition from 2D to 3D laparoscopy for the expert surgeon seemed to be very rapid without compromising patient safety [10]. Training on a simulated 3D model (compared to standard 2D) allows trainees to reach proficiency sooner [11]. Novice surgeons tended to perform better 
and felt much more comfortable with $3 \mathrm{D}$ in comparison to 2D laparoscopy. Even though previous task experience seemed to have an important impact on laparoscopic performance regardless of imaging modality, 3D laparoscopy seemed to facilitate the learning for novice surgeons [12]. One systematic review found out that $71 \%$ trials showed a reduction in performance time, $63 \%$ trials showed a significant reduction in error, and $3 \mathrm{D}$ laparoscopy appears to improve speed and reduce the number of performance errors when compared to 2D laparoscopy [13]. Our study showed that the turning point of the learning curve was a little earlier in 3D laparoscopy group (case $10^{\text {th }}$ ) than that in robot group (case $13^{\text {th }}$ ), which were both earlier than another paper (improvement of surgical performance in robot-assisted surgery for cervical cancer achieved after 28 cases) [14]. This difference was mostly due to the highly experienced surgeon who had more than 20 years' experience of 2D laparoscopic surgery, especially 2D laparoscopic hysterectomy and pelvic lymphadenectomy in cervical cancer.

Research suggested that with the advantage of delicate movement of robot instrument, robot-assisted systematic extended lymphadenectomy with total preservation of pelvic autonomic nerves did not compromise the radicality, and its surgical technique was feasible and safe [15]. The rate of perioperative complications of robotic surgery was $8.11 \%$ in our study, which was close to other reports $(14.4 \%$ [16] and $8.3 \%$ [17]). But another paper [18] suggested that $26 \%$ of reported events resulted in injury, $8.5 \%$ resulted in death, and $21 \%$ of injuries were attributed to operator-related error, $14 \%$ to technical system failure, $65 \%$ were not directly related to use of the robot, so it was important to continue to evaluate the occurrence of injuries during robot-assisted surgery in an effort to identify unique challenges associated with this advanced technology.

The differences of duration of operation, blood loss, peritoneal drainage of first 24 hours after operation, and the lymph nodes collected were not statistically significant in our research, which meant no obvious benefit from robotic surgery in the terms of short-term medical index. Our research also showed that both total hospitalization days and hospitalization days after operation were same in two groups, which meant no benefit from robotic surgery in the terms of hospitalization cost. In this study, we excluded the basic costs such as the upfront purchase costs, the annual maintenance fees or the costs coming from the increased operating room time [19]. The most instruments of 3D laparoscopic surgery are similar with those of traditional laparoscopic surgery, except for the 3D endoscope lens systems. But the instruments of robotic laparoscopic surgery are more complicated. The higher cost of robotic laparoscopic surgery came from the procedure-specific robot cost includes 4-arm robot draping and cost for disposable assistant's instruments specifically used for robotic surgery [20]. There is one paper which suggests that the use of robotics should be limited to well-powered, randomized clinical trials in a limited field of research [9]. When considering the almost 7 times higher cost of each operation in robot group than that in 3D group, not to mention the much higher cost of purchase, repairs and maintenance of equipment, we suggest further study about the cost-effect of robotic hysterectomy and pelvic lymphadenectomy in cervical cancer.

There were several limitations in this study. First, we did not study the learning curves of surgeons without laparoscopic experience, so we could not decide the potential effect of 3D cameras or robotic laparoscopy system in teaching laparoscopic skills. Second, the data of long term following-up are still needed to further analyze the cost-effect of robotic hysterectomy and pelvic lymphadenectomy in patients with cervical cancer.

In conclusion, the turning point of the learning curve of 3D laparoscopic hysterectomy and pelvic lymphadenectomy is earlier than that of robotic surgery in patients with cervical cancer, and there is no obvious benefit from robotic surgery than 3D surgery in the terms of short-term medical index and hospitalization cost. But the cost of each operation in robot group was much higher than that in 3D group. So we suggest further study about the cost-effect of robotic hysterectomy and pelvic lymphadenectomy in cervical cancer.

\section{Acknowledgements}

This study was supported by National Natural Science Foundation of China (grant No.31371452 to Hua Jiang) and Foundation from Science and Technology Commission of Shanghai Municipality (grant No.15JC1403202 to Hua Jiang).

\section{Competing Interests}

None of the authors have a conflict interest.

\section{References}

1. Yim GW, Kim YT. Robotic surgery in gynecologic cancer. Curr Opin Obstet Gynecol. 2012; 24:14-23.

2. Cela V, Freschi L, Simi G, et al. Fertility and endocrine outcome after robot-assisted laparoscopic myomectomy (RALM). Gynecol Endocrinol. 2013; 29(1):79-82.

3. Serati M, Bogani G, Sorice P, et al. Robot-assisted sacrocolpopexy for pelvic organ prolapse: a systematic review and meta-analysis of comparative studies. Eur Urol. 2014; 66(2): 303-18.

4. Collinet $\mathrm{P}$, Leguevaque $\mathrm{P}, \mathrm{Neme} \mathrm{RM}$, et al. Robot-assisted laparoscopy for deep infiltrating endometriosis: international multicentric retrospective study. Surg Endosc. 2014; 28(8): 2474-9. 
5. Liu H, Lu D, Wang L, et al. Robotic surgery for benign. Cochrane Database Syst Rev. 2012; 2:CD008978.

6. Tapper AM, Hannola M, Zeitlin R, et al. A systematic review and cost analysis of robot-assisted hysterectomy in malignant and benign conditions. Eur J Obstet Gynecol Reprod Biol. 2014; 177:1-10.

7. Tuschy B, Berlit S, Brade J, et al. Solo surgery--early results of robot-assisted three-dimensional laparoscopic hysterectomy. Minim Invasive Ther Allied Technol. 2014; 23(4): 230-4.

8. Park YS, Oo AM, Son SY, et al. Is a robotic system really better than the three-dimensional laparoscopic system in terms of suturing performance?: comparison among operators with different levels of experience. Surg Endosc. 2016; 30(4):1485-90.

9. Heemskerk J, Bouvy ND, Baeten CG. The end of robot-assisted laparoscopy? A critical appraisal of scientific evidence on the use of robot-assisted laparoscopic surgery. Surg Endosc. 2014; 28(4):1388-98.

10. Kyriazis I, Özsoy M, Kallidonis P, et al. Integrating Three-Dimensional Vision in Laparoscopy: The Learning Curve of an Expert. J Endourol. 2015; 29(6):657-60

11. Ashraf A, Collins D, Whelan M, et al. Three-dimensional (3D) simulation versus two-dimensional (2D) enhances surgical skills acquisition in standardised laparoscopic tasks: A before and after study. Int J Surg. 2015; 14:12-6.

12. Özsoy M, Kallidonis $P$, Kyriazis I, et al. Novice surgeons: do they benefit from 3D laparoscopy? Lasers Med Sci. 2015; 30(4):1325-33.

13. Sørensen SM, Savran MM, Konge L, et al. Three-dimensional versus two-dimensional vision in laparoscopy: a systematic review. Surg Endosc. 2016; 30(1):11-23.

14. Yim GW, Kim SW, Nam EJ, et al. Learning curve analysis of robot-assisted radical hysterectomy for cervical cancer: initial experience at a single institution. J Gynecol Oncol. 2013; 24(4):303-12.

15. Lee $\mathrm{YS}$, Chong GO, Lee $\mathrm{YH}$, et al. Robot-assisted total preservation of the pelvic autonomic nerve with extended systematic lymphadenectomy as part of nerve-sparing radical hysterectomy for cervical cancer. Int J Gynecol Cancer. 2013; 23(6):1133-8.

16. Yim GW, Kim SW, Nam EJ, et al. Perioperative complications of robot-assisted laparoscopic surgery using three robotic arms at a single institution. Yonsei Med J. 2015; 56(2):474-81

17. Göçmen A, Şanlıkan F, Uçar MG. Robot-assisted hysterectomy vs total laparoscopic hysterectomy: a comparison of short-term surgical outcomes. Int J Med Robot. 2012; 8(4):453-7.

18. Manoucheri E, Fuchs-Weizman N, Cohen SL, et al. MAUDE: analysis of robotic-assisted gynecologic surgery. J Minim Invasive Gynecol. 2014; 21(4):592-5.

19. Xie Y. Cost-effectiveness of robotic surgery in gynecologic oncology. Curr Opin Obstet Gynecol. 2015; 27(1):73-6.

20. Reynisson P, Persson J. Hospital costs for robot-assisted laparoscopic radical hysterectomy and pelvic lymphadenectomy. Gynecol Oncol. 2013;130(1):95-9. 